\title{
Countries y barrios privados en Yerba Buena, Gran San Miguel de Tucumán, Argentina: nuevas formas de expansión urbana
}

\author{
Matilde Malizia* \\ Pablo Paolasso*
}

Las metrópolis latinoamericanas han experimentado el surgimiento de nuevas formas de apropiación del espacio urbano. Aparecen en el espacio la construcción de edificios inteligentes, urbanizaciones cerradas y proyectos de elitización residencial. Si bien estos elementos se estudiaron para caracterizar las grandes metrópolis, es poco lo que se conoce respecto a las ciudades intermedias.

En este estudio se examina si los caracteres desarrollados para definir el avance de las urbanizaciones cerradas en las grandes metrópolis pueden adaptarse al análisis de una ciudad intermedia como el Gran San Miguel de Tucumán (Argentina). Dada su dotación de infraestructura y servicios, esta ciudad es la más importante del noroeste de Argentina y a menudo funciona como capital regional.

Palabras clave: ciudades intermedias, urbanizaciones cerradas, Gran San Miguel de Tucumán, segregación socioespacial.

Fecha de recepción: 2 de octubre de 2008.

Fecha de aceptación: 31 de marzo de 2009.

Countries and Private Neighborhoods in Yerba Buena, Gran San Miguel de Tucumán, Argentina: New Forms of Urban Expansion

Latin American metropolises have experienced the emergence of new forms of appropriation of urban space. This space has witnessed the construction of intelligent buildings, closed urbanizations and residential elitization projects. Although these elements were studied to characterize large metropolises, little is known about intermediate cities.

This study examines whether the characters developed to define the advance of gated communities in large metropolises can adapt to the analysis of an intermediate city such as Gran San Miguel de Tucumán (Argentina) Its supply of infrastructure and services makes this the most important city in the northeast of Argentina and it often functions as a regional capital.

Key words: intermediate cities, gated communities, Gran San Miguel de Tucumán, socio-spatial segregation.

* Instituto Superior de Estudios Sociales (ISES), Consejo Nacional de Investigaciones Científicas y Técnicas (Conicet), Universidad Nacional de Tucumán. Correo electrónico: matumalizia@yahoo.com.ar.

ESTUDIOS DEMOGRÁFICOS Y URBANOS, VOL. 24, NÚM. 3 (72), 2009, 583-613 


\section{Las transformaciones urbanas en América Latina durante los noventa}

Las investigaciones referidas a las ciudades latinoamericanas -sobre todo a las grandes metrópolis- en los últimos años han puesto de manifiesto el progresivo proceso de fragmentación en su funcionamiento y el notable crecimiento que han ocurrido en ellas (Prévôt Schapira, 2000; Borsdorf e Hidalgo, 2004: 22).

Las ciudades, que se veían ante todo como lugares en donde se conjugaban el progreso y la modernidad -como afirma Prévôt Schapira- han pasado por un proceso de dualización en su estructura espacial y social como resultado de la combinación de complejos factores relacionados con el avance del capitalismo global y con los patrones culturales e históricos de las diferentes sociedades, entre otras cuestiones. Estas urbes son el territorio en donde múltiples procesos de globalización adquieren un carácter concreto y localizado, un espacio donde se materializan las contradicciones de la globalización económica. Esto se explica mediante una dualidad: por un lado poseen una gran concentración de poder empresarial y son el terreno clave para la sobrevaloración de la economía corporativa y, por el otro, concentran una cantidad desproporcionada de habitantes en situación de desventaja y permiten que se reproduzca la subvaloración de dichos habitantes (Sassen, 2007: 98).

Durante años estas ciudades crecieron al influjo de una economía sustentada en el modelo keynesiano que se basaba en la sustitución de importaciones y cuyas estructuras podían explicarse conforme a diferentes modelos que se ajustaban a la realidad en forma bastante precisa (Griffin y Ford, 1980; Borsdorf, 1982; Bähr y Mertins, 1981). A partir de mediados de la década de los setenta y con mayor ímpetu desde fines de los ochenta, las ciudades transitaron por un proceso de profundas e importantes transformaciones. Se produjo principalmente una reducción en el ritmo de su crecimiento y hubo reformas sociales y políticas que modificaron las bases del desarrollo urbano. Si bien el perímetro de las ciudades continúa aumentando, la tasa de crecimiento se redujo fuertemente. Tales cambios obligaron a replantear esos modelos de análisis para adecuarlos a las nuevas realidades. De ese modo han surgido, en la actualidad varias interpretaciones sobre la estructura de las ciudades, que pueden observarse en los trabajos de autores como Borsdorf (2003a: 38) y Janoschka (2002). 
En los años noventa se logró un notable crecimiento económico en la mayoría de los países de América Latina, lo cual tendió a producir formas similares de asentamiento de la población, reforzando la construcción de cierto tipo de urbanizaciones que incluyen medidas de seguridad e idealizan la vida campestre (Borsdorf e Hidalgo, 2004: 22). Sin embargo este desarrollo económico no acarreó prosperidad para toda la sociedad; se tradujo en un quiebre socioespacial en las ciudades que se manifestó en la creciente diferenciación entre los grupos sociales. Hubo un aumento en la brecha entre pobres y ricos que provocó distanciamiento social y fragmentación espacial, y puso en evidencia un proceso de transformación de la morfología social urbana y suburbana. El sistema territorial quedó en una situación de desequilibrio en los aspectos físicos y sociales porque en las ciudades se generaron fragmentos separados de los núcleos tradicionales, los cuales quedaron encerrados dentro de fronteras que propician la segregación social (Vidal Koppmann, 2002). Tal vez la manifestación más visible de este proceso haya sido la eclosión de espacios residenciales cerrados y de un conjunto de infraestructuras -carreteras, centros comerciales, de entretenimiento y otros- vinculadas a la aparición de los mismos. ${ }^{1}$

Estos fraccionamientos no constituyen una novedad en las ciudades latinoamericanas, pero su desarrollo se ha acelerado a partir de los noventa y ha dado lugar a una nueva fisonomía tanto espacial como social (Janoschka, 2002).

Si bien estos procesos se han estudiado con bastante detalle para las grandes metrópolis latinoamericanas, ${ }^{2}$ son menos conocidos para las ciudades que les siguen en la jerarquía urbana. ${ }^{3}$ No obstante, algunos autores -como Borsdorf e Hidalgo (2004)-aseguran que estos procesos han tenido una rápida difusión en ciudades de diferente tamaño.

El Gran San Miguel de Tucumán -en adelante GSMT-, ciudad con cerca de 800000 habitantes y una serie de funciones que la convierten en una verdadera capital regional, forma parte del conjunto de urbes intermedias de Argentina, donde suceden ciertos procesos de frag-

${ }^{1}$ Según la ciudad o país de que se trate, se conocen como urbanizaciones cerradas, fraccionamientos cerrados, cotos cerrados, barrios privados, country club, o gated communities.

${ }^{2} \mathrm{Al}$ respecto pueden consultarse los textos colectivos editados por Cabrales Barajas (2002) e Hidalgo, Trumper y Borsdorf (2005), entre otros.

${ }^{3}$ En América Latina la investigación urbana ha sido, en primer lugar, investigación sobre la gran ciudad. 
mentación y segregación socioespacial similares a los que ocurren en otras ciudades del mismo tamaño y, de manera parcial, a los que ocurren en el principal aglomerado del país: el Área Metropolitana de Buenos Aires (AMBA).

En las últimas décadas el desarrollo urbano del GSMT fue intenso. Sólo entre 1965 y 1991 duplicó su superficie (Müller, 2002: 116). Desde entonces, luego de una fase de bonanza económica en Argentina que impulsó notablemente al sector de la construcción, su crecimiento ha continuado al mismo ritmo, pero esta vez no solamente en sentido horizontal, también vertical.

En el área central de la ciudad se multiplicaron las edificaciones de mayor altura y aumentó la superficie del área comercial. En los bordes la expansión adquirió múltiples formas, desde viviendas sociales construidas por el Estado hasta urbanizaciones cerradas de lujo. Dicha expansión tuvo un notorio sesgo espacial. Así, mientras hacia el este, norte y noreste el crecimiento se produjo sobre la base de la construcción de extensos barrios residenciales a cargo del Estado, hacia el oeste el crecimiento estuvo sobre todo vinculado a la aparición de las urbanizaciones cerradas.

Se ha producido entonces, ya desde fines de la década de 1970 pero con mayor énfasis a partir de la de 1990, un intenso proceso de segregación socioespacial en el GSMT, y han aparecido con fuerza ciertos fenómenos que hasta entonces habían sido característicos de las grandes metrópolis.

De este modo cabe preguntar si ciertos procesos que acontecen en las grandes metrópolis, como el aumento de la inseguridad, el crecimiento socioespacial desmedido y la influencia del mercado inmobiliario en la oferta urbana residencial, se reproducen en ciudades intermedias como el GSMT. De manera paralela se podría indagar si la profusión de urbanizaciones cerradas en ciudades de menor tamaño es producto de la difusión de un estilo residencial exclusivo para determinados grupos sociales, como sugieren Borsdorf e Hidalgo (2004). Asimismo convendría cuestionar si el adoptar este estilo de vida ubicaría a sus residentes en determinada posición en la estructura social, es decir, si les otorgaría cierto estatus social dentro de su grupo de pertenencia.

En este artículo trataremos de responder a tales interrogantes analizando para ello los procesos de transformación acaecidos en los últimos años en el GSMT, en especial en un sector del mismo: el municipio Yerba Buena, en el sector occidental de la ciudad, que fuera 
durante años el área de residencia preferente de las clases más acomodadas de la sociedad, y donde hoy es posible ver la aparición de gran parte de estos nuevos fenómenos ya reseñados en la bibliografía.

Se conjetura que a diferencia de lo que sucede en las grandes ciudades, los procesos de avance de estas nuevas formas de apropiación del espacio urbano no tienen el mismo alcance ni la misma profundidad en una ciudad intermedia como el GSMT.

La aparición de las urbanizaciones cerradas genera, al igual que en las grandes metrópolis, una profundización aún mayor de la segregación socioespacial. Sin embargo dicho proceso se encuentra todavía en forma inconclusa en el GSMT.

Sobre la base de estas conjeturas se torna relevante estudiar si los procesos ya observados en las grandes ciudades se replican en las que siguen en la jerarquía urbana y si es que ocurren de una manera similar o diferente, teniendo en cuenta que la población, y sobre todo las funciones de las mismas respecto a su entorno, son bastante más reducidas.

\section{Urbanizaciones cerradas y segregación socioespacial en ciudades latinoamericanas}

Tanto en el pasado como en la actualidad las ciudades de América Latina han presentado similitudes en cuanto a su estructura funcional y socioespacial; sin embargo su composición social y sus estructuras políticas son muy divergentes (Borsdorf, 2003b; Bähr y Mertins, 1993: 5).

Las transformaciones socioespaciales que ocurrieron en estos países a partir de los noventa se vieron reforzadas y aceleradas por procesos neoliberales globales (Mertins, 2003: 192). Los mismos implicaron cambios económicos y sociales en el contexto sectorial y regional cuyas repercusiones se manifestaron en dichas ciudades. ${ }^{4}$ Las reformas económicas de los años noventa apuntaban a contraer el Estado y generaron un proceso de polarización social que se vio reflejado en la nueva redistribución espacial de las ciudades, en la cual son cada vez más los ciudadanos que buscan una organización privada y

${ }^{4}$ Estos cambios se refieren al aumento de la flexibilización económica, la concentración regional de la economía, la centralización de las decisiones en las metrópolis, el crecimiento del sector informal, el aumento del desempleo o subempleo, el aumento de la polarización socioeconómica, la segregación socioespacial, la creciente criminalidad y la desregulación del mercado urbano y de las normas de planificación, entre otros. 
eficiente de su vecindario que les provea los servicios que antes eran públicos.

La aplicación de estas reformas puso en evidencia una marcada tendencia hacia formas globales de vida, vivienda y trabajo (Janoschka, 2002). Surgieron nuevas formas comercializables, redituables y valiosas para el mercado, dirigidas principalmente a los ganadores de las transformaciones económicas. ${ }^{5}$ Las ciudades latinoamericanas cambiaron su estructura y fisonomía: aparecieron nuevos elementos característicos, como los muros y las cercas alrededor de barrios y calles. ${ }^{6}$ Espacial y urbanísticamente hablando estos cambios se expresaron en el aumento de edificios inteligentes, urbanizaciones cerradas y condominios verticales, en su mayoría construidos mediante la asociación de lo público y lo privado-public-private partnership.

Con la liberalización del mercado del suelo, la especulación inmobiliaria y la privatización de la seguridad, el mercado inmobiliario renovó sus estrategias de venta y comenzó a ofrecer lugares seguros para vivir. Sin embargo el ciudadano que no pudo o no quiso acceder a esos lugares cerró sus barrios a imitación de los espacios residenciales para darles garantía de seguridad. Así, sólo algunos grupos sociales pudieron permitirse el aislamiento.

Este tipo de emprendimientos cerrados se distribuyen en los alrededores de las metrópolis generalmente sin una planificación previa, obedeciendo a las leyes del mercado de oferta y demanda. Se genera un proceso de transformación territorial que se plasma de dos maneras. Primero mediante la urbanización de fracciones de territorio destinadas a usos no urbanos, y segundo, con la extensión caótica del tejido periurbano, que origina áreas con escasez de servicios y de baja calidad ambiental (Vidal Koppmann, 2000).

Dentro del proceso de desarrollo de las ciudades latinoamericanas se produce una fragmentación territorial que determina la dispersión de la infraestructura y de las funciones urbanas y genera una amplia variedad de formas urbano estructurales y de desarrollo (Mertins, 2003: 193). Esta fragmentación territorial va de la mano de la segregación social, y ambos procesos se retroalimentan. Con una perspectiva amplia se observa que conviven distintos grupos sociales en espa-

${ }^{5}$ Svampa (2003: 79) plantea que en Argentina existen dos grupos: los ganadores y los perdedores de las transformaciones socioeconómicas.

${ }^{6}$ Borsdorf (2003b) refiere que desde los orígenes de la ciudad moderna existieron en América Latina muros dentro de las metrópolis, los cuales nunca funcionaron como límites logísticos. 
cios reducidos, pero con una mirada más minuciosa se percibe que la distancia social entre dichos grupos es cada vez mayor. A pesar de esto es posible advertir que la relación que se establece entre ambos sectores aumenta, dado que se necesitan mutuamente para el desarrollo de la vida diaria.

De esta manera, la estructura urbana cambió hacia un organismo totalmente fragmentado. Entendiendo que la fragmentación se refiere al cambio en el esquema de interdependencia entre los distintos sectores de la ciudad, en donde los mismos tienden a convertirse en entes autónomos, donde la vida gira en torno a pequeños fragmentos (Girola, 2005: 6). En la actualidad la estructura urbana se expresa en la instalación de urbanizaciones cerradas, centros comerciales y de entretenimiento, entre otros, equipados con barreras, murallas, sistemas de seguridad, etcétera.

Los enclaves para los sectores altos y los destinados a los sectores pobres coexisten dentro de la ciudad y caracterizan a la misma en el presente, distinguiéndola de la que existía tan sólo 30 años atrás. ${ }^{7}$ Esto se identifica como urbanización difusa, expresión que da cuenta de un nuevo modelo que apunta a sistemas cerrados sin heterogeneidad y sin conexión entre ellos (Vidal Koppmann, 2000).

La tendencia al aislamiento en complejos cerrados se impuso en la mayoría de las metrópolis de América Latina y en algunas ciudades intermedias. Se produjo la llegada de las clases alta y media alta a zonas habitualmente populares, y con ello se intensificaron las desigualdades sociales y la fragmentación y segregación socioespacial. Anteriormente los espacios suburbanos eran ocupados, aunque no de manera exclusiva, por las clases bajas, mientras que en la actualidad están siendo habitados también por los sectores alto y medio que se establecen en diversos complejos habitacionales, comerciales, de servicio, de entretenimiento, etcétera.

Esto marca una nueva distribución espacial que resalta la ruptura con la tradicional expansión de los barrios de la clase alta. Se evidencia en las metrópolis una marcada tendencia hacia una ciudad de islas de riqueza, producción, consumo y precariedad (Janoschka, 2002).

Continuando con esta idea Harvey (1998: 126) resalta que el posmodernismo contiene una concepción fragmentada del tejido urbano en donde se combinan y se superponen formas del pasado. El diseño

\footnotetext{
${ }^{7}$ Para Borsdorf (2003b) la tendencia a la segregación y separación del tejido urbano tiene una larga tradición en América Latina e implica una ruptura entre el espacio público y el privado.
} 
urbano busca tener en cuenta las historias locales, las necesidades y los requerimientos de la sociedad con el fin de generar formas arquitectónicas especializadas y adaptadas a los clientes. La apariencia de la ciudad y la manera de organizar sus espacios forman la base material a partir de la cual pueden evaluarse y realizarse una serie de prácticas sociales. Una de las formas de ciudad resultante está integrada por comunidades urbanas cada una de las cuales constituye un barrio independiente dentro de un conjunto de barrios urbanos que a su vez configuran ciudades dentro de la ciudad.

No se trata del total abandono de los antiguos modelos de análisis funcional y socioespacial de las ciudades, sino por el contrario, de la actualización de los mismos a partir de la incorporación de nuevos elementos propios de esta nueva fase de crecimiento urbano. Los modelos resultantes se basan en los anteriores, reflexionan sobre ellos, los modifican y sostienen con el fin de absorber los cambios del mundo actual.

A partir del modelo de diferenciación socioespacial de la gran ciudad latinoamericana se elaboró uno similar para las ciudades intermedias basándose en varios ejemplos de Argentina, Colombia, Perú, etc. (Mertins, 1995). Allí también se desarrollaba, aunque de manera inconclusa, el esquema de anillos concéntricos y cuñas, aunque aparecían en la periferia, muchas veces entremezclados, barrios de vivienda popular, barrios semilegales, ilegales y los de las clases media y alta. ${ }^{8}$ Este modelo elaborado para ciudades cuyo crecimiento se produjo bajo un régimen típicamente fordista, ya preanunciaba, sin embargo, la fragmentación de estas urbes.

Según los modelos elaborados para las ciudades cuyo crecimiento se produjo conforme a las reglas del neoliberalismo durante los años noventa, la fragmentación se ha vuelto la norma, como lo muestra Janoschka (2002). En estas urbes posmodernas se multiplica la creación de urbanizaciones cerradas en la periferia, desdibujando con ello la estructura en cuña que se desarrollaba previamente. Se incrementan los centros comerciales y de entretenimiento en toda el área, no solamente en las zonas contiguas a la clase alta. También se produce una mejora sustancial en las infraestructuras de transporte, con la construcción de vías de acceso rápidas para facilitar el traslado hacia las distintas áreas de la ciudad. Se promueve el traslado de la producción

\footnotetext{
${ }^{8}$ Borsdorf (1976) elaboró un modelo similar, donde las áreas concéntricas en vez de ser círculos concéntricos son cuadrados concéntricos, pues en general el centro de las ciudades latinoamericanas tiene una estructura en damero.
} 
industrial hacia los suburbios, la cual se aglutina en parques de negocios o centros de actividad logística. Los elementos celulares que aparecen en la periferia se encuentran cada vez más involucrados con las apetencias del mercado inmobiliario y de desarrolladores y brokers inmobiliarios.

\section{Fuentes y metodología}

El municipio Yerba Buena se encuentra ubicado al oeste del GSMT y cuenta con una población aproximada de 50000 habitantes. Concentra la mayor cantidad de urbanizaciones cerradas -countries y barrios privados- de toda la provincia y presenta una marcada heterogeneidad social entre sus habitantes.

En el desarrollo de esta investigación se considera dentro de la unidad de estudio a los residentes en countries y barrios privados, empleados que trabajan en los mismos, actores sociales del ámbito público y privado -agentes inmobiliarios, constructores, urbanistas, funcionarios-, proveedores de bienes y servicios y habitantes de Yerba Buena y del GSMT en general, todos ellos en estrecha vinculación con el desarrollo integral de estos emprendimientos urbanísticos.

En una primera etapa se analizó la escasa cartografía que ha elaborado la municipalidad de Yerba Buena sobre la localización de las urbanizaciones cerradas. Las observaciones preliminares de campo mostraron que dicha cartografía no se encontraba actualizada, por lo que debió examinarse la totalidad del área de estudio a fin de constatar la información obtenida, localizar de manera más precisa los emprendimientos construidos en la zona e incorporar los que no estuvieran registrados. Así se elaboró un mapa que contiene la ubicación precisa de la totalidad de los emprendimientos residenciales bajo estudio y se construyó una tabla de datos con la información recabada en el transcurso del trabajo de campo. Es pertinente mencionar que durante el mismo la observación que se llevó a cabo siempre fue del tipo que recomienda Guber (1991: 95), es decir, observación con participación.

Del mismo modo, durante el trabajo de campo se practicaron entrevistas abiertas en profundidad y se entablaron conversaciones informales (Taylor y Bodgan, 1990: 15) con residentes de estos emprendimientos, vecinos, proveedores de bienes y servicios, empleados, agentes inmobiliarios, administradores y constructores, entre otros. El objetivo fue recabar información acerca de los procesos que posibili- 
taron el surgimiento de los countries y barrios privados en la zona, la instalación y posterior desarrollo de los mismos, las relaciones que han entablado las personas que los habitan y las vinculadas a ellos, y la fragmentación espacial y segregación social resultantes, entre otras cuestiones, contrastando la información reunida con algunos de los supuestos teóricos.

Posteriormente se efectuó un análisis estadístico de los datos proporcionados por el Censo Nacional de Población, Hogares y Vivienda 2001, que llevó a cabo el Instituto Nacional de Estadística y Censo (INDEC) con la finalidad de estudiar las características principales de la población residente en el área de estudio.

Finalmente se analizaron algunas notas periodísticas que han publicado diferentes medios de comunicación, y varios folletos publicitarios que emitieron las agencias inmobiliarias encargadas de comercializar estos emprendimientos.

\section{El Gran San Miguel de Tucumán}

El GSMT -cuyo núcleo incluye a la capital de la provincia de Tucumán: San Miguel de Tucumán- abarca hoy día un conjunto de localidades que se distribuyen entre cinco departamentos de la provincia, incluyendo cinco municipios y una comuna rural (mapa 1) ${ }^{9}$ En el año 2001 contaba con un poco más de 730000 habitantes (cuadro 1) y se estima que en la actualidad se acerca a 800000 (Encuesta Permanente de Hogares, INDEC, segundo semestre de 2006).

La ciudad de San Miguel de Tucumán fue fundada en 1565 y trasladada a su sitio actual en 1685. Constituyó uno de los primeros emplazamientos españoles en el actual territorio argentino y rápidamente se convirtió en un nodo principal en el camino entre Buenos Aires y el Alto y Bajo Perú (Paolasso, 2004). En la actualidad es, por su tamaño y por las funciones que desempeña, la urbe más importante del norte de Argentina. Su crecimiento estuvo estrechamente vinculado con el desarrollo de la agroindustria azucarera, cuyo florecimiento comenzó en el último tercio del siglo XIX. Posteriormente, a lo largo del siglo XX, su expansión demográfica y espacial fue acelerada.

${ }^{9}$ La provincia de Tucumán se divide en 17 departamentos. Los mismos se encuentran subdivididos en municipios y comunas rurales dependiendo del número de habitantes y del tipo de funciones que desempeñan. El municipio tiene mayor jerarquía que la comuna rural. 


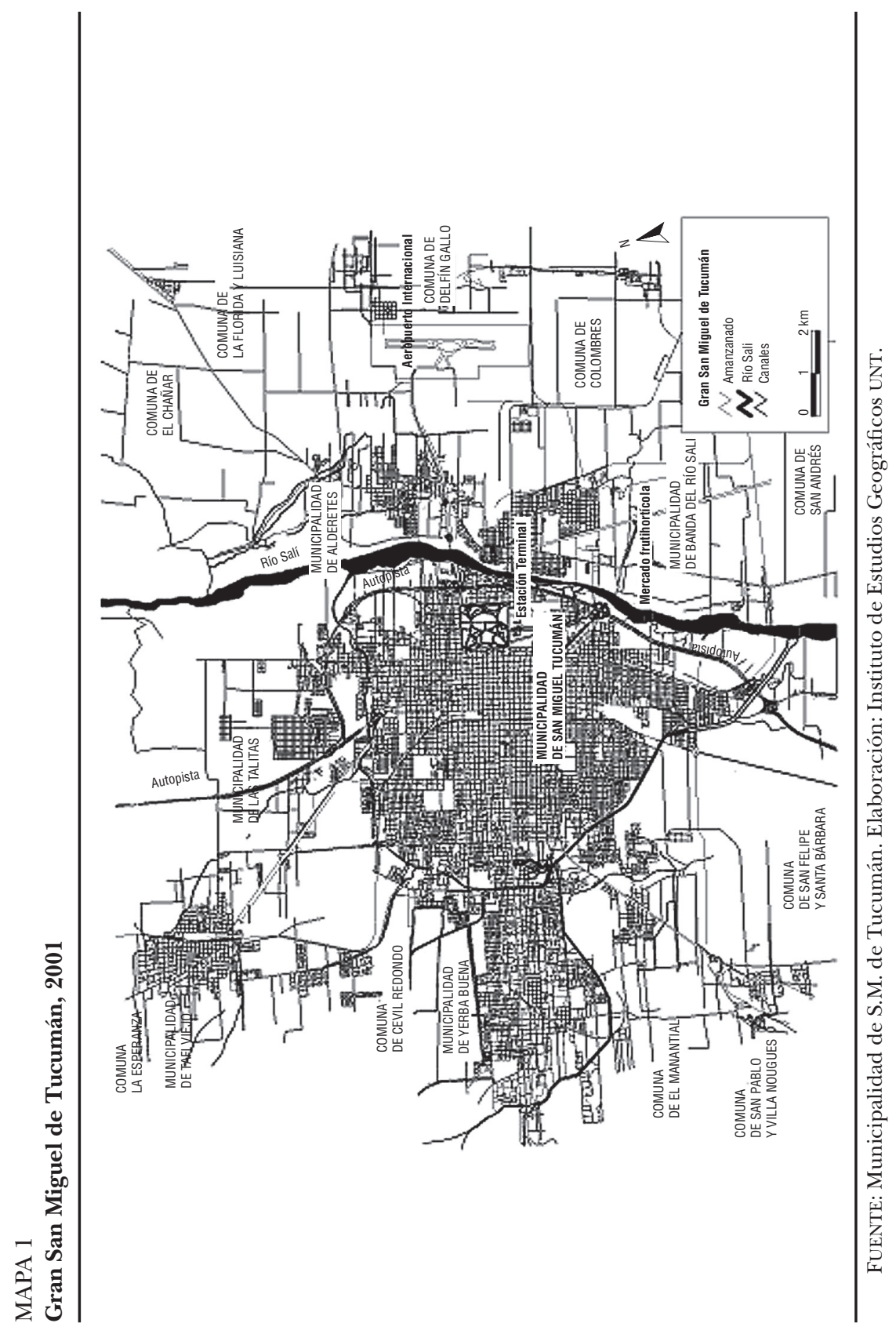




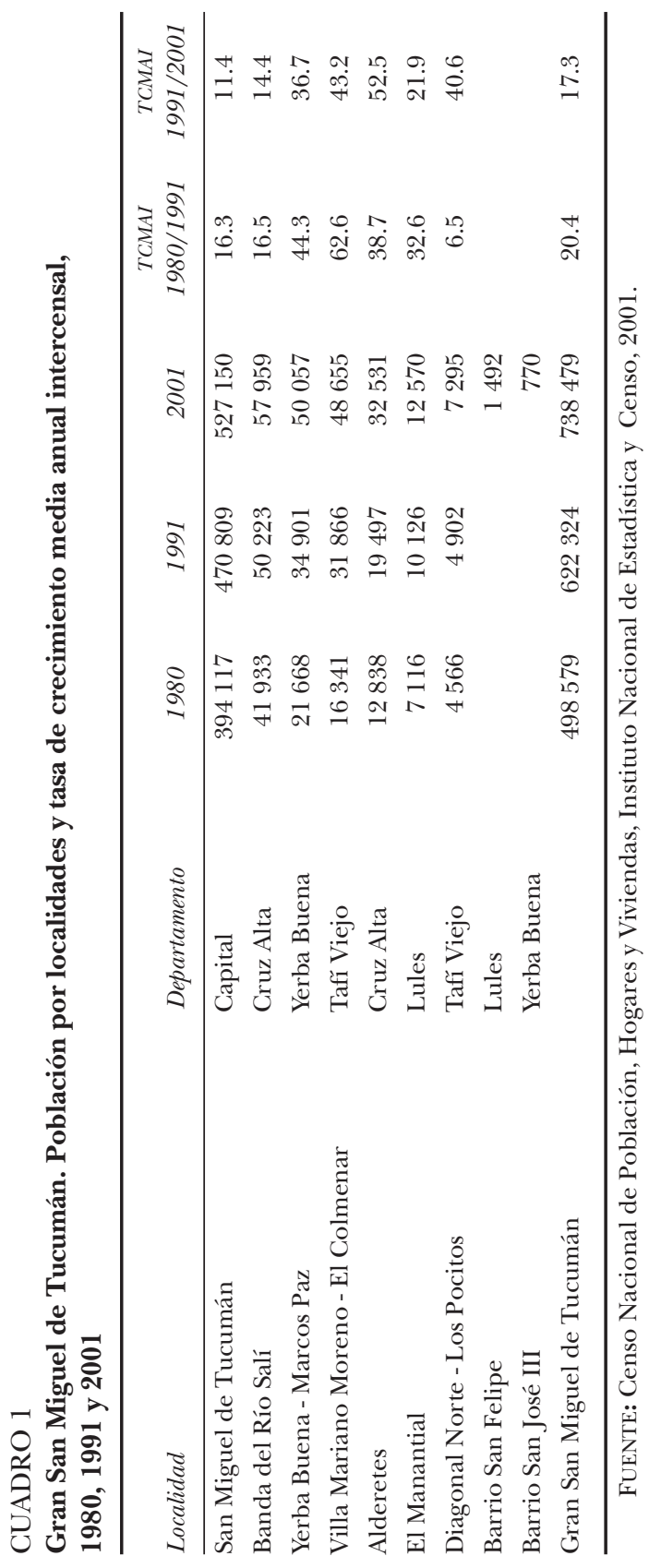


En su desarrollo se han producido fenómenos típicos de otras ciudades de América Latina. La expansión hacia la periferia provocó la aparición de grandes áreas ocupadas por barrios de las clases bajas -villas miseria en la terminología argentina- que contrastan con los barrios de las clases altas -hoy bajo la forma de urbanizaciones cerradas-. A ello se suman el aumento de la segregación socioespacial y los severos problemas ambientales (Mansilla, 2001).

Tales procesos se produjeron como resultado de las limitaciones que tuvo el desarrollo capitalista que promovió la agroindustria azucarera en la provincia. Esto se conjugó con una estructura demográfica caracterizada por el pasaje de un régimen pretransicional a uno transicional, y el accionar errático de la clase dirigente de la provincia. Estos factores generaron intensos flujos de migrantes de las áreas rurales hacia la capital que ocasionaron un rápido crecimiento de la ciudad, el cual no fue acompañado por un aumento de la infraestructura y los servicios básicos para la población (Paolasso, 2004).

\section{La segregación socioespacial en el Gran San Miguel de Tucumán}

En las últimas décadas el desarrollo urbano del GSMT estuvo determinado por intensos cambios en el uso del suelo. El área destinada al sector agropecuario fue disminuyendo paulatinamente al mismo tiempo que creció el área para viviendas y otros usos urbanos -centros comerciales, instituciones públicas y privadas, etc.- Los lotes agropecuarios se transformaron en sitios baldíos hasta que se desarrollaron en ellos nuevas formas de uso urbano. El baldío, por lo tanto, se convirtió en el elemento típico de la zona de crecimiento urbano. ${ }^{10}$ Inicialmente los cambios se dieron en forma circular alrededor del centro urbano y a lo largo de la avenida principal de acceso a Yerba Buena. Más tarde las áreas de crecimiento circulares casi desaparecieron y las áreas de alta dinámica de cambio se limitaron a zonas puntuales del GSMT; Yerba Buena fue una de ellas (Müller, 2002: 122). ${ }^{11}$

En estos espacios comenzaron a coexistir distintas formas de utilizar el suelo: junto con la ocupación ilegal de terrenos para viviendas populares se construyeron conjuntos habitacionales de vivienda social,

\footnotetext{
${ }^{10}$ Baldío es un terreno de dominio del Estado o de un particular, esté en uso o no, que sea susceptible de apropiación privada mediante ocupación.

${ }^{11}$ Müller analiza el proceso de segregación socioespacial en el Gran San Miguel de Tucumán a lo largo del periodo comprendido entre 1965 y 1991.
} 
y viviendas de residencia permanente o de fin de semana para las clases media, media alta y alta. Hacia finales de la década de los ochenta y principios de los noventa la dirección del crecimiento urbano estuvo determinada por las preferencias de la demanda. Algunas personas de alto poder adquisitivo se instalaron en los lugares cercanos a las conexiones viales importantes, y éste fue el caso de Yerba Buena.

Hacia 1995 Mertins (1995: 495) elaboró una descripción del GSMT en la que distinguió dos zonas relevantes: el centro y oeste, donde se advertía ya la preeminencia de viviendas de las clases media alta y alta, y el resto de la ciudad, donde las viviendas son sobre todo de las clases media y media baja. Si bien aún predominaban en el centro barrios de los estratos superiores y al mismo tiempo no se observaba una notable extensión del centro comercial, los elementos sectoriales ya estaban presentes. Por entonces comenzaron la migración de los sectores altos de la sociedad hacia el oeste del GSMT y la instalación de un subcentro en creciente desarrollo que ofrecía diversos bienes y servicios. Esto propició la reparación y la creación de las principales avenidas de acceso. La convivencia de distintos sectores sociales en las diversas zonas de la ciudad ponía en evidencia los crecientes procesos de fragmentación espacial y segregación social que ya estaban aconteciendo en el aglomerado.

\section{Procesos de segregación socioespacial durante los noventa en el Gran San Miguel de Tucumán: countries y barrios privados en Yerba Buena ${ }^{12}$}

Durante los años noventa ocurrieron intensas transformaciones en el crecimiento urbano del GSMT. En ciertas zonas como Las Talitas o Alderetes, en el norte y el noreste de la ciudad, dicho crecimiento estuvo liderado por el de los barrios que construyó el Estado para los estratos medios bajos y bajos de la sociedad. Asimismo aparecieron en forma celular, dispersos en donde había disponibilidad de terrenos fiscales o baldíos, algunos asentamientos ilegales y semilegales, que si bien no constituían una novedad sí lo era su número, que se multiplicaba rápidamente.

Las clases más acomodadas comenzaron a migrar desde el centro de la ciudad hacia la periferia, en especial hacia el municipio Yerba

${ }^{12}$ Los datos que aparecen en este apartado fueron recogidos durante el trabajo de campo realizado en 2007. No se revelan los nombres de los entrevistados con el fin de resguardar su identidad. 
Buena en el oeste del GSMT, que se reconocía por entonces como una zona residencial de la clase alta, reforzando este patrón. Allí, al crecimiento urbano con residencias exclusivas se le sumaron nuevas formas de habitar: las urbanizaciones cerradas.

En sus orígenes Yerba Buena surgió como un enclave suburbano desconectado espacialmente de la capital, un lugar de descanso con casas de fin de semana destinado a la clase alta de la sociedad que buscaba escapar del ya excesivo congestionamiento urbano y disfrutar de espacios al aire libre y en contacto directo con la naturaleza.

En 1906 se creó el primer núcleo urbano, cívico y jurídico de Yerba Buena, llamado Marcos Paz, que comprendía 25 manzanas en las cuales se erigieron la iglesia, la comisaría y el juzgado de paz (La Gaceta, 10 de diciembre de 2006). Sin embargo, antes de que esto sucediera ya habían ocurrido varios intentos de trazado urbano en los alrededores de la denominada Plaza Vieja - plaza fundacional ubicada en La Rinconada- y en la intersección de las actuales avenidas Aconquija y Solano Vera, los cuales datan de 1850.

Durante la primera mitad del siglo xx la emigración de familias de la clase alta no alcanzó magnitudes significativas, pero entre mediados de los sesenta y finales de los ochenta Yerba Buena se convirtió en el área residencial por excelencia de los grupos más acomodados de la sociedad. La construcción de sus respectivas residencias, en convivencia con las primeras quintas, cañaverales y asentamientos alrededor de las zonas agrícolas, produjo un incremento significativo de la densidad poblacional y de las infraestructuras de servicios. Comenzó a poblarse de viviendas exclusivas - de alta calidad, con superficies amplias y terrenos espaciosos- para uso permanente, dentro de un intenso proceso de transición de lo rural a lo urbano.

La importación de capitales que ocurrió en el país luego del establecimiento de la economía dolarizada en 1991 impulsó la llegada de nuevos valores y estilos de vida y alentó la generación de nuevos espacios urbanos (Janoschka, 2003). Se favorecieron entonces, dentro de una intensa fase de recuperación económica y liberalización de los mercados, las oportunidades de edificación y difusión de nuevos espacios residenciales. Este fenómeno afectó primero al AMBA y luego se difundió por las ciudades que le siguen en la jerarquía urbana, entre ellas el GSMT.

En el caso de la ciudad de Tucumán las urbanizaciones cerradas no pueden ser consideradas como un fenómeno que se produjo espontáneamente por las reglas del mercado. Por el contrario, su profu- 
sión fue producto de la difusión de un fenómeno desde el AMBA hasta las ciudades del interior del país. Una residente de un country lo expresa de la siguiente manera: "en Buenos Aires ya existían, alejados de la ciudad para que la gente se relaje en espacios abiertos y verdes...". Tal difusión se llevó a cabo mediante diversos medios de comunicación que tenían como corolario la adecuación de una nueva forma de vivir, en barrios residenciales ubicados cerca de las principales urbes pero en zonas selectas: un lugar donde sentirse diferente y en contacto con sus pares, donde se combinan las actividades culturales y educativas con las de esparcimiento y comerciales.

Uno de los agentes mediadores que contribuyeron a la propagación de este tipo de emprendimientos residenciales fueron, y lo continúan siendo, las agencias inmobiliarias y las empresas constructoras, que mediante fuertes campañas de mercadeo dirigen la manera de habitar la ciudad por medio de un nuevo estilo residencial. Sin embargo los lineamientos que se utilizan para llevar a cabo estas campañas varían de una ciudad a otra, pues adaptan elementos globales al ámbito local. Dicha adaptación depende en gran medida de la normatividad local.

En Tucumán la oferta principal de estas urbanizaciones radica en la consecución de un estilo de vida diferente junto a un determinado estatus social: vivir en un country o barrio privado significa adquirir, como expresa Bourdieu (1998: 351), una posición dentro de la estructura social "este country es el mejor de Tucumán por el lugar donde está ubicado, la vista que tiene y la cancha de golf que, según dicen es la mejor, le da mucha jerarquía [...]. Vivir en un country es una cuestión elitista", afirma un residente.

La cuestión de la seguridad también aparece entre las opiniones de algunos residentes de countries y barrios privados de Yerba Buena: "mira yo me he venido más por seguridad que por otra cosa... yo quería más seguridad", pero con una connotación diferente respecto al AMBA, donde lo que prima en la oferta inmobiliaria es la seguridad que se adquiere viviendo en esos lugares. De acuerdo a los entrevistados, se resalta que se contrata una sensación de seguridad, no la seguridad propiamente dicha. Un administrador de un country lo explica de la siguiente manera:

lo que se contrata es sensación de seguridad, la gente quiere ver al tipo caminando por ahí. Se podría decir que la seguridad es preventiva porque la realidad es que si te quieren entrar lo pueden hacer [...]. Pero en general las personas están equivocadas si creen que vivir en un country o 
barrio privado es cien por ciento seguridad, vivir adentro o afuera tiene sus riesgos.

En el municipio Yerba Buena el primer country que se construyó fue el Yerba Buena Golf Country Club, inaugurado en 1978. Cuenta en su interior con una sede social y deportiva y un amplio campo de golf, entre otros elementos. Una de las primeras residentes permanentes del country relató: "Yo vivo en el country hace 18 años, en ese momento éramos 10 familias las que vivíamos ahí... todo era muy verde, no tenías a nadie al lado, tu vecino más próximo estaba lejos...". En esta aseveración resalta la exclusividad que otorga el residir en una urbanización cerrada, además de los beneficios de vivir en un área verde y alejada del ruido de la ciudad. Las viviendas construidas en esta urbanización solían utilizarse principalmente como casas de fin de semana, y las ocupaban algunas familias pertenecientes a los grupos más acomodados de la sociedad.

Fue apenas a partir del año 1991 cuando las urbanizaciones cerradas comenzaron a multiplicarse rápidamente en el ámbito local. Estos emprendimientos residenciales aparecen como el reflejo de un estilo de vida que se intensificó a partir de los noventa y son el producto de una nueva formación económica que rompe claramente con las tradicionales pautas de estructuración urbana. El habitar en los mismos se transformó en un símbolo de estatus social (El Periódico, 4 de diciembre de 2005). Sus residentes generan estrategias de distinción (Bourdieu, 1998: 223) para diferenciarse del resto de la sociedad. Esto implica destacarse entre sus pares -que viven afuera de estos emprendimientos o en urbanizaciones similares-al considerarse ganadores dentro de su propia clase social. Por lo general estas estrategias no están destinadas a establecer diferencias con personas o grupos considerados pobres o pertenecientes a la clase baja, dado que tales diferencias están establecidas de antemano. En este caso la relación entre el adentro y el afuera se plantea no sólo desde la identificación más o menos mimética con el otro, también desde el reconocimiento de la distancia; se convierte en una mirada hacia arriba o hacia abajo, una mirada desde una posición más que desde una situación.

La crisis social, política y económica que explotó en el país en diciembre de 2001 interrumpió temporalmente el auge de estos emprendimientos residenciales, interrupción que se manifestó en la paralización de algunas obras, la caída de las ventas inmobiliarias y el aumento del precio del suelo, entre otras cuestiones. No obstante, la fase de re- 
cuperación económica que ocurrió en los años siguientes facilitó las oportunidades para realizar inversiones directas de capital. Los operadores inmobiliarios afirman que el costo de la tierra y la vivienda superó los valores anteriores a la crisis (Vidal Koppman, 2006). Algunos sectores empresariales comenzaron a destinar fondos al rubro inmobiliario y con ello impulsaron el desarrollo y la venta de estos espacios residenciales "la mayoría [de los lotes del country] se vendió en el 2001 porque en ese momento los terrenos eran del [banco] HSBC. Mucha gente tenía la plata en el banco y los agarró el corralito entonces invirtieron la plata en esos lotes que el banco ofrecía, pasaban la plata del banco al lote"; el mismo entrevistado menciona que estas urbanizaciones "surgieron por la influencia del mercado inmobiliario, ellos sacan un producto como estas urbanizaciones y las terminan imponiendo".

La determinación de áreas para uso residencial en la ciudad responde al proceso de especulación inmobiliaria y a sus estrategias de venta, que direccionan la demanda proveniente de una importante franja de la población. Los agentes inmobiliarios aprovechan las lagunas de la normatividad que regula la construcción de estos emprendimientos y obtienen así importantes ganancias. Las urbanizaciones cerradas simbolizan, según estos agentes, la perfección de un estilo de vida, y se transforman en la principal oferta inmobiliaria, que rompe claramente con las tradicionales pautas de estructuración urbana. El municipio Yerba Buena tiende a expandirse hacia sus bordes sobre terrenos que anteriormente se utilizaban como parcelas de cultivo. Estos terrenos ofrecen la ventaja de que su precio de compra es relativamente bajo en comparación con los costos de venta finales que adquieren una vez realizadas las obras de infraestructura pertinentes para la instalación de la nueva urbanización cerrada. Una señora que reside en un country lo explica de la siguiente manera:

acá $[\ldots]$ se los construye en terrenos baratos [...], se los compra por nada, se los desmonta, se los pone lindo y después se los vende carísimo. Es un emprendimiento económico. Los espacios descampados están a orillas de la ciudad por eso se los construye donde están. En la ciudad no hay espacio para comprar y hacer un country, está todo muy amontonado.

En el año 2007 Yerba Buena concentraba la mayor cantidad de urbanizaciones cerradas del aglomerado ${ }^{13}$ y se convirtió en uno de los

${ }^{13}$ En el trabajo de campo llevado a cabo por los autores durante el año 2007 se constató que en el resto del aglomerado de GSMT las urbanizaciones cerradas son escasas. 
municipios con mayor crecimiento demográfico de éste en los últimos 20 años (cuadro 1). Había entonces 49 emprendimientos residenciales de este tipo, de los cuales 39 son barrios privados y 10 countries. ${ }^{14}$ En una inmobiliaria de la zona explican las diferencias entre ambos de la siguiente manera: "En el barrio privado no hay instalaciones para hacer diversas actividades; a lo sumo tienen una placita. El único es el Lomas Tenis [un barrio privado] que tiene, como su nombre lo indica, canchas de tenis. Por el contrario el country cuenta con servicios comunes como sede, club house, pileta y canchas de todo tipo".

Autores como Svampa (2004), Carballo (2002), Vidal Koppmann (2002) y Tella (2000) diseñaron distintas tipologías para clasificar a las urbanizaciones cerradas. De acuerdo a las mismas los countries se identifican como condominios de carácter exclusivo y elitista que exaltan la valoración de la vida al aire libre y la práctica de deportes. Para ello cuentan con instalaciones deportivas y sociales de uso común, como canchas de fútbol, paddle y tenis, campos de golf, alberca y sede social destinados al uso comunitario y familiar. El barrio privado no dispone generalmente de equipamiento deportivo y recreativo para uso común, pero es la oferta más difundida entre las urbanizaciones cerradas. Constituye la expresión de una nueva lógica de ocupación del espacio urbano por los grupos con ingresos medios altos y altos.

Se han clasificado los emprendimientos atendiendo a la fase de desarrollo urbanístico en que se encuentran, considerando como fase inicial el desmonte del terreno, y como la más avanzada la urbanización terminada, es decir, construida y habitada en su totalidad (cuadro 2). De acuerdo con ello sólo 35, entre countries y barrios privados, están habitados, es decir, se encuentran en la fase 6 o la 7, y los 14 restantes se distribuyen entre las primeras 5 fases.

La rapidez con que se incrementó la construcción de urbanizaciones cerradas en Yerba Buena trajo consigo una aparición simultánea de inconvenientes y beneficios para el área que las contiene. Entre los problemas se advierte que su llegada no implicó una mejora sustancial de la infraestructura de servicios como la provisión de agua potable o

${ }^{14}$ Según el Código de Ordenamiento Urbano de 1994 de la municipalidad de Yerba Buena, se define a la urbanización cerrada como urbanización especial. La misma es toda fracción de tierra cuya superficie sea igual o mayor a $2500 \mathrm{~m}^{2}$ o tenga las características de manzanas conformadas. Puede estar destinada para fines habitacionales -grupo de dos o más viviendas que conforman un conjunto de características constructivas y diseños homogéneos- o no habitacionales - uno a más edificios cuyo destino no sea vivienda y que por su función genere una infraestructura necesaria para el fin por el cual ha sido creado. 
la instalación de cloacas ( La Gaceta, 10 de diciembre de 2006) ${ }^{15} \mathrm{Un}$ vecino observa que: "esos barrios tienen muchos problemas, casi ninguno tiene hechas las cloacas... claro que las cloacas en Yerba Buena son deficientes, no están hechas en todos lados [señala algunos puntos en un mapa] y a algunos countries eso no les importa". Por otra parte acarrearon una mejora sustancial de las principales avenidas de acceso que conectan al municipio con la capital de la provincia, la pavimentación de calles principales y secundarias y la apertura de nuevas calles, todo ello con el consecuente aumento de los flujos de vehículos. Sin embargo, como expresa Hidalgo (2004), en algunos casos esto poco tiene que ver con la planificación territorial y las estrategias tendentes a alcanzar un uso armónico del espacio.

Con el devenir de los años en Yerba Buena se fue consolidando la coexistencia de diversos grupos sociales. Junto a los barrios planificados, las áreas residenciales, ${ }^{16}$ la ocupación ilegal de terrenos y los asentamientos precarios, se edificaron urbanizaciones cerradas. La cercanía espacial de los sectores más antagónicos de la sociedad ha provocado que los sectores más bajos se encuentren cada vez más seguido ante una doble situación: o rodeados por las urbanizaciones cerradas que se han construido en sus proximidades, o expulsados hacia zonas aún más periféricas de la ciudad. Esto pone de manifiesto el aumento de la fragmentación espacial y la segregación social, cuyo contraste más llamativo resulta de la distancia socioeconómica entre ambos grupos. ${ }^{17}$ Dicho contraste es evidente en el caso bajo estudio: 16 de las 35 urbanizaciones cerradas habitadas tienen por lo menos como uno de sus límites una franja ocupada por casas humildes. Además, el proceso de crecimiento vertiginoso de las urbanizaciones cerradas ocurre en un contexto donde la pobreza tiene valores importantes. De acuerdo a un informe elaborado por el INDEC (2008) durante el cuarto trimestre de 2007 y el primero de 2008 era pobre $29.1 \%$ de la población del aglomerado GSMT, y $8 \%$ se encontraba por debajo de la línea de indigencia.

En el municipio Yerba Buena la localización y distribución espacial de las urbanizaciones cerradas no responde a un patrón de dis-

${ }^{15}$ Otro ejemplo de ello es la localidad de Pilar, en Buenos Aires. Si bien contiene numerosas urbanizaciones cerradas, todavía hay sectores con calles de tierra, ausencia de redes de agua y saneamiento y hospitales deteriorados (Thuillier, 2005).

${ }^{16}$ Dentro del conjunto de áreas residenciales se incluyen las viviendas construidas por particulares en terrenos adquiridos para tal fin.

${ }^{17}$ La fragmentación espacial y la segregación social se entienden como la separación de diferentes grupos sociales en una ciudad o área geográfica de acuerdo a diferencias étnicas, religiosas, económicas, culturales, etc. (Roitman, 2003). 


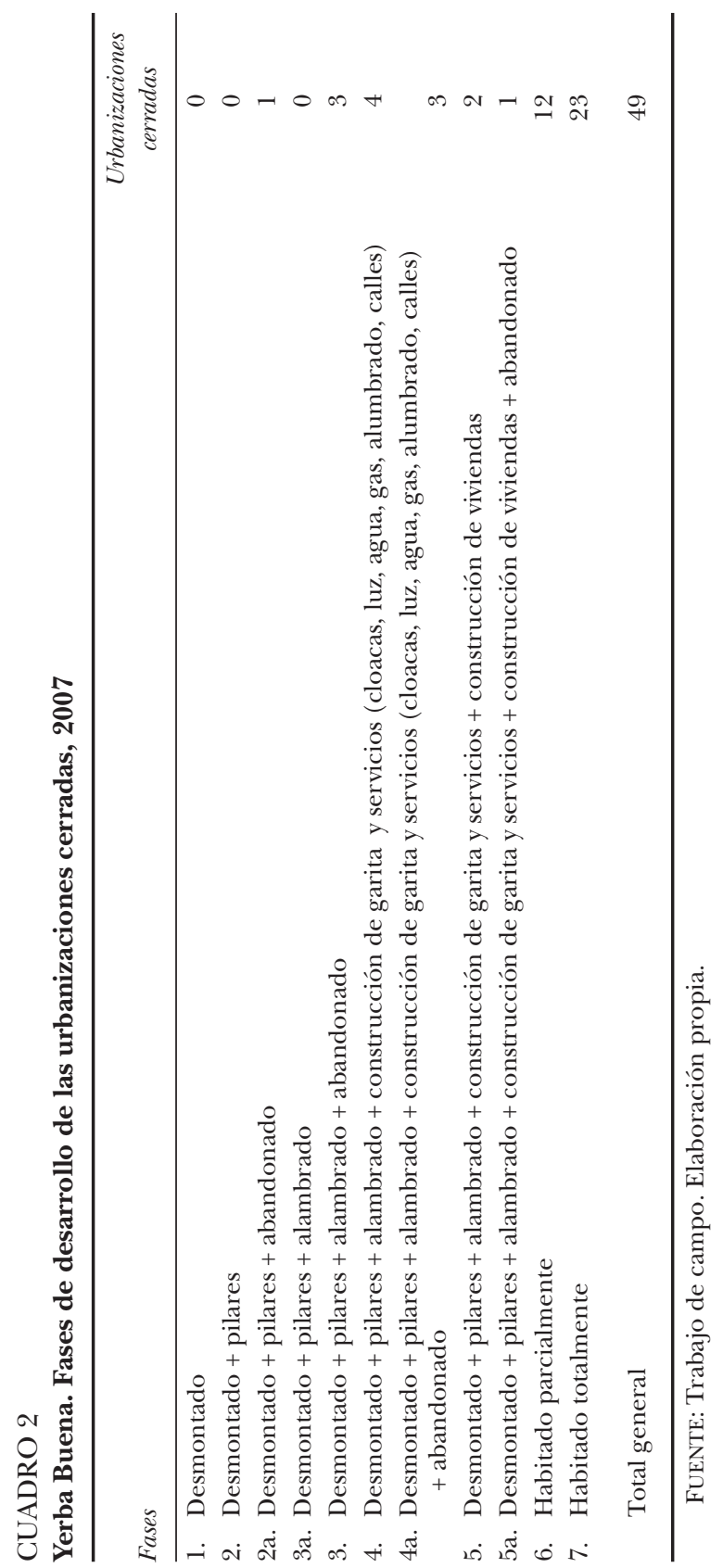


tribución homogéneo definido. Por el contrario, tal distribución se define en función de la oferta de terrenos para usos urbanos, que por lo general no tiene restricciones y se origina, como ya dijimos, en los criterios económicos y normativos vigentes. Según un agente de una inmobiliaria local: "no existe reglamentación para estas urbanizaciones y las pocas reglamentaciones que hay para la planificación de estos barrios muestra que están todas en falta o están violando alguna reglamentación".

Esta falta de normas la evidencia la pérdida de espacios verdes y áreas destinadas a usos agrícolas -especialmente cañaverales-y su reemplazo por diferentes tipos de emprendimientos urbanísticos y comerciales, principalmente countries y barrios privados. Un empleado de un country explica: "antes lo único habitado era la diagonal [actual Calle Vía Sur/Diagonal Sur/Calle Vía Norte, antigua vía del tren]. Todos los barrios que uno ve ahora son nuevos, de los últimos 10 años, antes todo era campo y cultivos. Por eso los countries se instalaron sobre esos campos y no sobre espacios en los que había gente". Un vecino agrega: "estas tierras eran todas cañaverales y todavía quedan algunas fincas de caña pero no creo que duren mucho más, a todos los cañaverales los están sacando para hacer countries".

Originariamente el sur de Yerba Buena era la zona más densamente poblada. Allí se ubicaban, principalmente, las calles que conectaban el municipio con la ciudad capital, las casas de los primeros terratenientes y una vertiente de agua. Un vecino comenta al respecto: "Por esa zona [el sur] había algunas casas grandes... de las haciendas". En los años siguientes se fue poblando la zona norte del municipio y en la actualidad quedan todavía pequeñas extensiones de tierra con cultivo de caña de azúcar.

Las urbanizaciones cerradas que ocupan lotes de dimensiones amplias se ubican en los márgenes del municipio, en áreas que antiguamente se utilizaban para el cultivo, en general de cañaverales. Entre ellos está el Country Jockey Club de Tucumán, ubicado sobre el límite norte, que se asienta sobre 140 ha y, hacia el límite oeste el Country Las Yungas, que se extiende sobre 105 ha. Por el contrario, los emprendimientos significativamente más pequeños se construyen en las proximidades de las áreas centrales del municipio, en terrenos que se usaban anteriormente como pequeñas chacras donde se cultivaban plantas de hortalizas. Entre ellos figuran el barrio privado Quinta Anzorena, asentado sobre 3.8 ha, la Villa Delfina, que ocupa 4 ha y Miraflores de 1 ha. (mapa 2). 


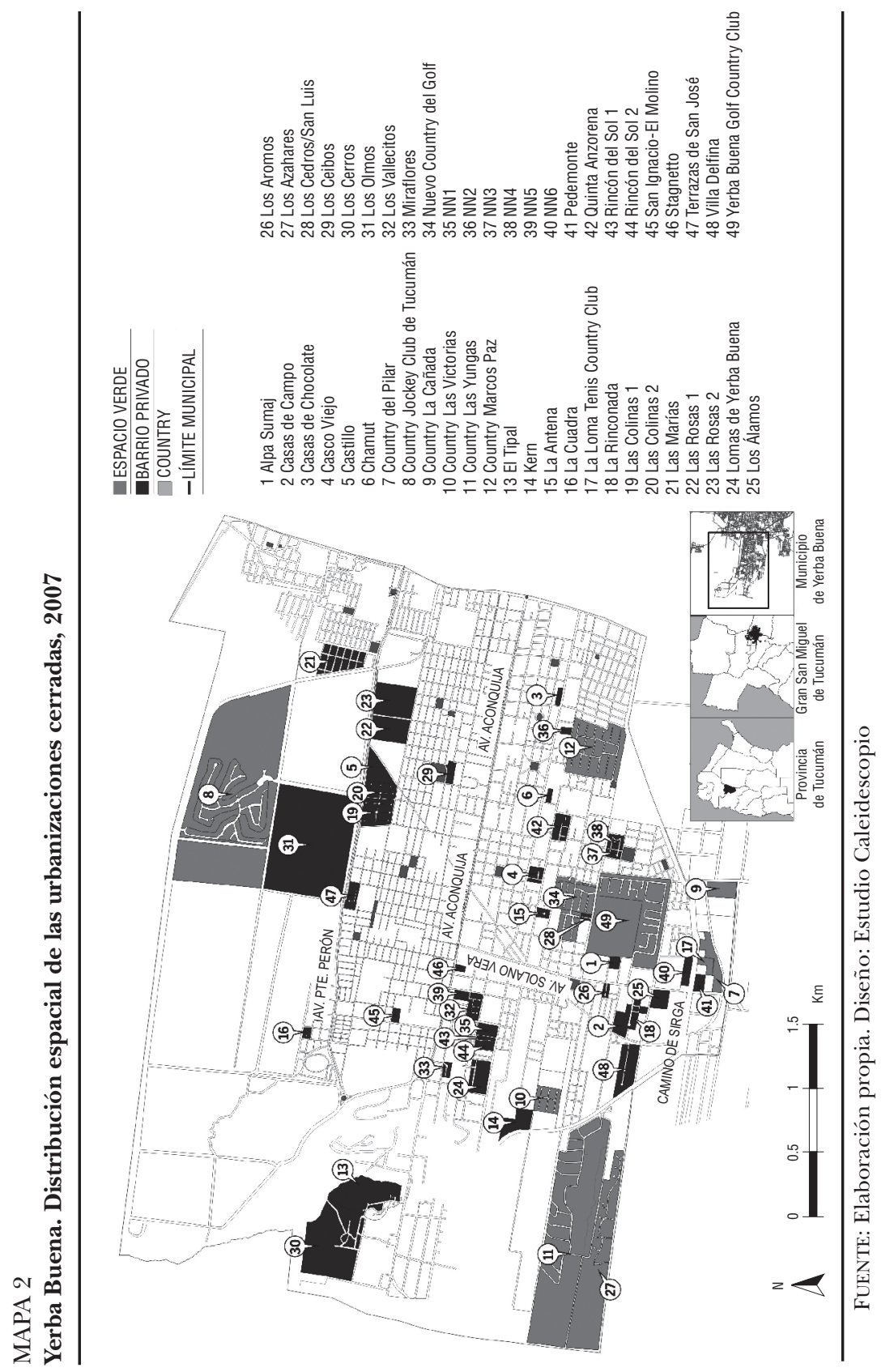


Actualmente este municipio tiene una superficie de $38 \mathrm{~km}^{2}$, de los cuales $17 \%$ está ocupado por urbanizaciones cerradas asentadas sobre un total de $6.5 \mathrm{~km}^{2}$. El avance de estos emprendimientos sobre áreas destinadas a usos agrícolas y espacios verdes -como una parte de la ladera del cerro San Javier, ubicado en el límite oeste- es cada vez más evidente. Hasta hace unos diez años, aproximadamente, el paisaje urbano mostraba cierto equilibrio entre la naturaleza y los espacios residenciales, por el contrario hoy día se caracteriza por la presencia de fisuras que resaltan la pérdida gradual de espacios verdes y la debilitada conexión entre los distintos sectores del municipio.

Finalmente la llegada de los countries y barrios privados a Yerba Buena trajo aparejados grandes cambios en el sector comercial. Los más profundos y notables ocurrieron aproximadamente en el transcurso de los últimos diez años a lo largo de la principal vía de acceso, la avenida Aconquija. Se construyó allí una amplia variedad de locales de bienes y servicios -centros bancarios, médicos, comerciales y shoppings, entre otros- que si bien todavía coexisten con los antiguos negocios de la zona, paulatinamente los van reemplazando y llegarán a eliminarlos por completo de la oferta comercial. También se inauguraron anexos de algunas oficinas públicas cuya sede principal está en la capital tucumana, como por ejemplo la Dirección General de Rentas y la Caja Popular de Ahorros, ambas instituciones provinciales (mapa 3).

Como resultado de este proceso de cambios se está generando en Yerba Buena una nueva centralidad que se caracteriza por la articulación de actividades urbanas de variada índole que a su vez atraen el establecimiento de nuevas actividades. ${ }^{18} \mathrm{Un}$ administrador de un barrio privado explica que: "ahora hay muchas oportunidades porque hay un mercado creciente de necesidades de consumo. Ahora acá tenés sucursales de todos los negocios grandes de Tucumán [municipio capital]. Yerba Buena tiene todo, como si fuese una ciudad grande".

Este crecimiento comercial influye de manera significativa en la disminución de las relaciones comerciales entre Yerba Buena y San Miguel de Tucumán. Anteriormente se consideraba que la capital tucumana era la fuente más importante para la provisión de los bienes y servicios que requería Yerba Buena. Ahora cada vez más personas optan por no trasladarse a la capital para realizar sus actividades cotidianas. Algunos residentes de urbanizaciones cerradas comentan que

${ }^{18}$ El grado de centralidad de un espacio varía según su capacidad de atracción y articulación de actividades (Licnerski, s.f.). 
"se va generando un circuito comercial [...] hay más bonanza económica"; "en el aspecto comercial [Yerba Buena] está cubierto, yo no voy más al centro".

\section{Conclusión}

Es innegable que en el GSMT, una ciudad intermedia, se ha fragmentado el tejido urbano. Han aparecido, como lo observa Janoschka (2002) en algunas metrópolis, islas de riqueza, consumo y precariedad; sin embargo no se ha producido allí una ruptura tajante con la tradicional distribución de los barrios de los sectores altos. Yerba Buena fue tradicionalmente un sector de la ciudad donde coexistieron diferentes clases sociales, aunque con predominio de las más altas. El espacio suburbano, a diferencia de lo reseñado por buena parte de la bibliografía sobre urbanizaciones cerradas, no estaba ocupado solamente por los sectores bajos, pues era evidente que convivían varios grupos de la sociedad.

La aparición de los emprendimientos residenciales de lujo vino a reforzar un patrón que ya existía, pero además generó una serie de nuevos procesos. Coexisten todavía hoy, aunque cada vez en menor medida, diferentes grupos sociales. Las estrategias de supervivencia generadas en ese sector de la ciudad por los grupos más empobrecidos se tornan cada vez más infructuosas debido a que el avance desmedido de los barrios privados y countries los va cercando y en muchos casos expulsando hacia la periferia. En definitiva, quienes viven en esos barrios buscan consciente o inconscientemente alejarse de los pobres, a quienes asocian con la inseguridad. El miedo y la inseguridad aparecen entonces como factores que atraviesan los discursos de sus residentes y se convierten, junto a la búsqueda de un mayor estatus social, en uno de los motivos centrales que conducen a adoptar a ese tipo de emprendimientos como residencias permanentes.

A diferencia de lo que sucede en las grandes metrópolis donde la fragmentación socioespacial es la norma, en el GSMT todavía es incipiente. La segregación socioespacial está promoviendo la dispersión de infraestructuras y funciones urbanas en forma aislada dentro del cuerpo urbano. En el caso de Yerba Buena esto es notorio. Hasta hace pocos años el grueso de la población adquiría buena parte de los bienes y servicios indispensables para su subsistencia en el municipio capital, pero hoy es posible ver a lo largo de la vía principal de Yerba Buena (avenida Aconquija) la generación gradual de una nueva cen- 


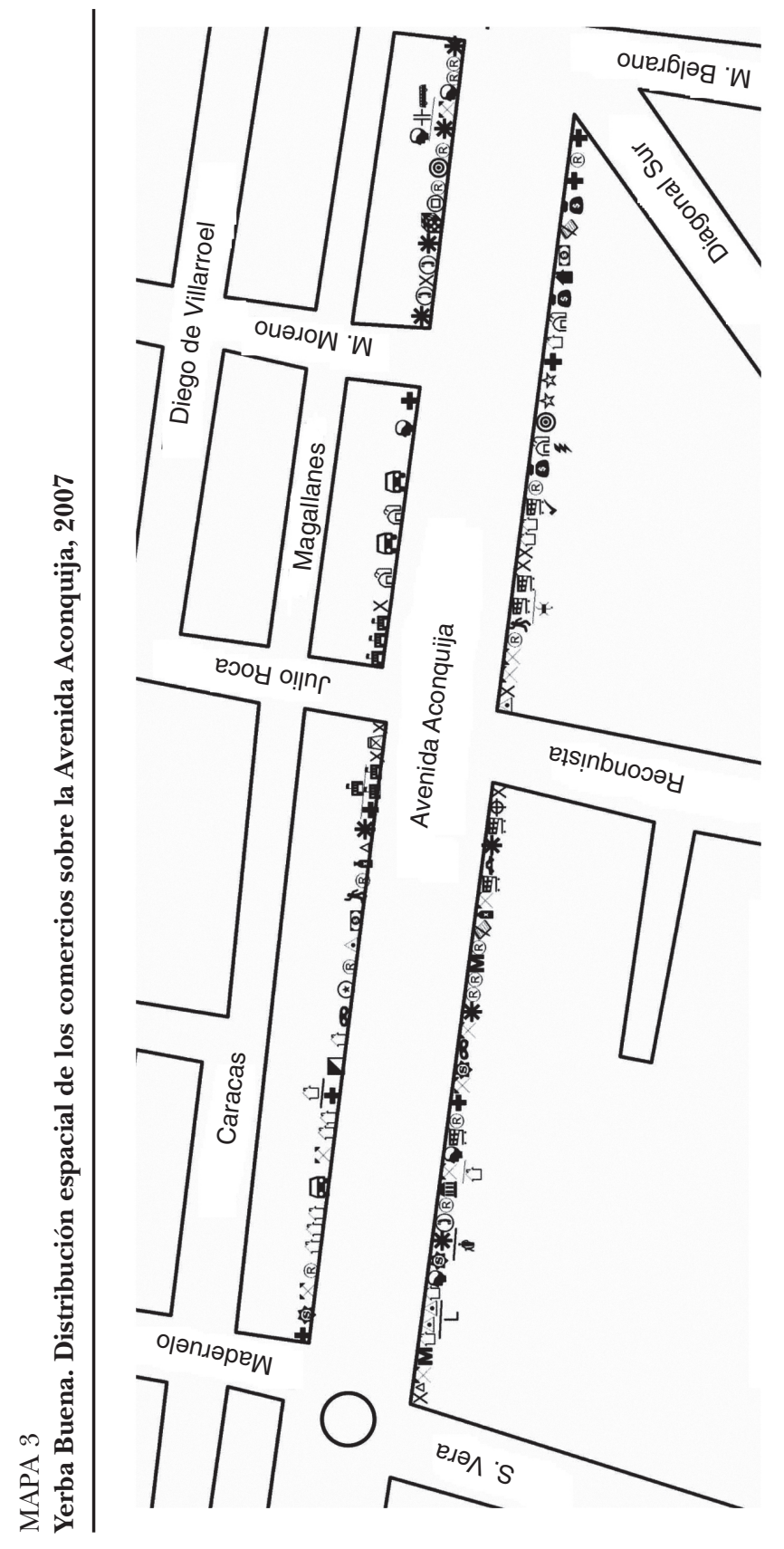




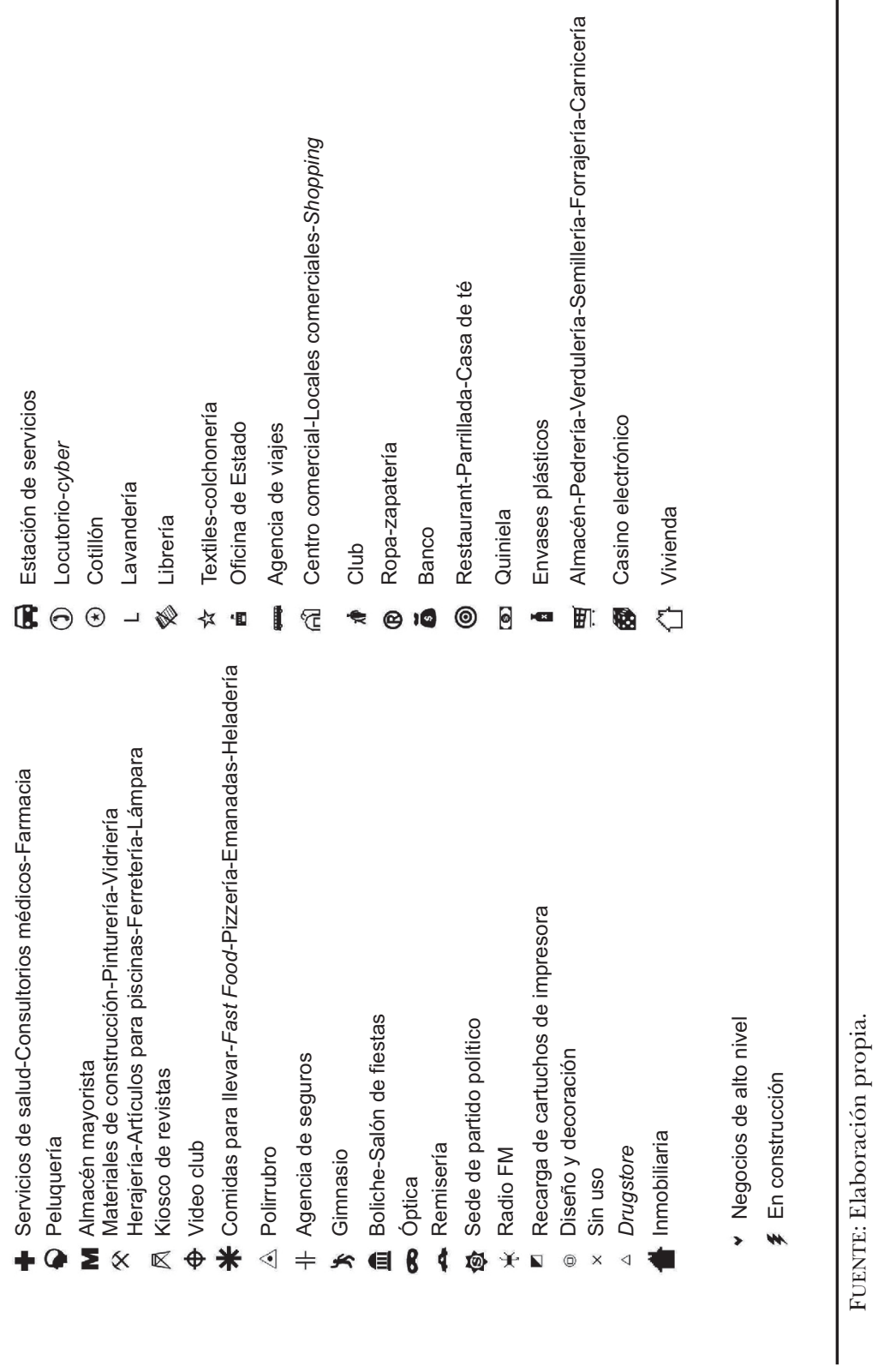


tralidad. Los habitantes de las urbanizaciones cerradas como de todo el municipio no deben ya moverse al tradicional CBD de San Miguel de Tucumán para proveerse de bienes y servicios, sino que pueden hacerlo allí mismo. Oficinas del Estado, bancos, compañías de seguros, tiendas de modas, salones de belleza, restaurantes, etc., han instalado allí sucursales -y en ocasiones las casas matrices- con la intención de satisfacer una demanda en continuo crecimiento de grupos sociales que tienen muy buen poder adquisitivo.

Las infraestructuras modernas que permiten vincular a estos emprendimientos con el resto de la ciudad comienzan apenas a construirse, lo cual marca una notable diferencia respecto de las grandes ciudades. En el caso de Yerba Buena se invierten algunas etapas: primero se instalan el country o el barrio privado y después, ante la presión y las influencias de sus habitantes, se construyen las infraestructuras y se proveen ciertos servicios que los vinculan al resto del cuerpo urbano. Esto se relaciona directamente con la forma en que se difunden las urbanizaciones cerradas desde una ciudad mayor hasta una intermedia, donde la especulación inmobiliaria y la imitación de los guiños y gestos de la gran ciudad desempeñan un rol central, más que la incidencia de cierto tipo de políticas.

El hecho de vivir en estos emprendimientos residenciales confiere a las personas que en ellos residen un significativo estatus social, y ello reviste cierta importancia para ellas. Más allá de la búsqueda de una vida apacible y saludable, rodeada de áreas verdes y en un ambiente seguro, vivir allí ubica a sus residentes en una elevada posición dentro de la estructura social. Este factor aparece como preponderante en gran parte de las entrevistas realizadas.

Finalmente, el avance de los countries y barrios privados en Yerba Buena le acarreó varios conflictos al municipio y, por ende, a su población preexistente.

A partir de los modelos de segregación socioespacial se observa que el GSMT atravesó en los últimos años un intenso proceso de transformación en su estructura urbana. El crecimiento de la ciudad en forma de islas rompió con el tradicional esquema de crecimiento en cuñas. Esa fragmentación, que es la característica predominante de dicho proceso, continúa desarrollándose. Sin embargo muchos de los aspectos reseñados para estas metrópolis se están manifestando recientemente y en algunos casos se encuentran en forma inconclusa. 


\section{Bibliografía}

Bähr, Jürgen y Günter Mertins (1993), "La ciudad en América Latina: población y sociedad", Eure, vol. 1, pp. 5-14.

Bähr, Jürgen y Günter Mertins (1981), "Idealschema der Sozialräumlichen Differenzierung Lateinamerikanischer Großstädte”, Geographische Zeitschrift, vol. 69, pp. 1-33.

Borsdorf, Axel (1976), "Valdivia und Osorno. Strukturelle Disparitäten in Chilenischen Mittelstädten”, Tübinger Geographische Studien, núm. 69.

Borsdorf, Axel (1982), "Die Lateinamerikanische Großstadt. Zwischenbericht zur Diskussion um ein Modell”, Geographische Rundschau, vol. 34, núm. 11, pp. $498-501$.

Borsdorf, Axel (2003a), "Cómo modelar el desarrollo y la dinámica de la ciudad latinoamericana”, Eure, vol. 29, núm. 086, pp. 37-49.

Borsdorf, Axel (2003b), "Hacia la ciudad fragmentada. Tempranas estructuras segregadas en la ciudad latinoamericana”, Scripta Nova, vol. 7, núm. 146 (122).

Borsdorf, Axel y Rodrigo Hidalgo (2004), "Formas tempranas de exclusión residencial y el modelo de la ciudad cerrada en América Latina. El caso de Santiago", Norte Grande, núm. 32, pp. 21-37.

Bourdieu, Pierre (1998), La distinción. Criterios y bases sociales del gusto, España, Taurus.

Cabrales Barajas, Luis Felipe (comp.) (2002), Latinoamérica: países abiertos, ciudades cerradas, México, Universidad de Guadalajara/UNESCO.

Cabrales Barajas, Luis Felipe (2005), "Estado del conocimiento sobre las urbanizaciones cerradas en Iberoamérica”, en O. Gutierrez (coord.), La ciudad y el miedo. VII Coloquio de Geografía Urbana, Gerona, Grupo de Geografía Urbana/Asociación de Geógrafos Españoles/Universitat de Girona.

Cabrales Barajas, Luis Felipe y Elia Canosa Zamora (2002), "Nuevas formas y viejos valores: urbanizaciones cerradas de lujo en Guadalajara”, en L.F. Cabrales Barajas (comp.), Latinoamérica: países abiertos, ciudades cerradas, México, Universidad de Guadalajara/UnESCO.

Carballo, Cristina Teresa (2002), "Buenos Aires y la urbanización cerrada: nuevas formas de apropiación del espacio urbano", en L.F. Cabrales Barajas (comp.), Latinoamérica: países abiertos, ciudades cerradas, México, Universidad de Guadalajara/ UNESCO.

Diario La Gaceta (2006), "Una ciudad que crece a pasos agigantados", 10 de diciembre.

Diario El Periódico (2005), "Los countries avanzan en Yerba Buena”, 4 de diciembre.

Girola, Florencia (2005), "Tendencias globales, procesos locales: una aproximación al fenómeno de los conjuntos residenciales con seguridad de la región metropolitana de Buenos Aires", Revista de Antropología Iberoamericana, núm. 43. 
Griffin, E. y L. Ford (1980), "A Model of Latin American City Structure”, Geographical Review, vol. 70, núm. 4, pp. 397-422.

Guber, R. (1991), El salvaje metropolitano, Buenos Aires, Legasa.

Harvey, David (1998), La condición de la posmodernidad. Investigación sobre los orígenes del cambio cultural, Buenos Aires, Amorrortu Editores.

Hidalgo, R. (2004), "De los pequeños condominios a la ciudad vallada: las urbanizaciones cerradas y la nueva geografía social en Santiago de Chile”, Eure, 30, núm. 91, p. 29-52.

Hidalgo, R., R. Trumper y A. Borsdorf (2005), Transformaciones urbanas y procesos territoriales. Lecturas del nuevo dibujo de la ciudad latinoamericana, Santiago, Serie GEOlibros/Academia de Ciencias Austriaca/Okanagan University College.

INDEC (2001), Censo de población y vivienda 2001, Instituto Nacional de Estadística y Censo <www.indec.gov.ar>.

Janoschka, M. (2002), "Urbanizaciones privadas en Buenos Aires: ¿hacia un nuevo modelo de ciudad latinoamericana?", en L.F. Cabrales Barajas (coord.), Latinoamérica: países abiertos, ciudades cerradas, México, Universidad de Guadalajara, pp. 287-318.

Janoschka, M. (2003), "Nordelta, ciudad cerrada. El análisis de un nuevo estilo de vida en el Gran Buenos Aires”, Scripta Nova, vol. 7, núm. 146, p. 121.

Licnerski, J. R. (s.f.), "Las grandes intervenciones urbanas como espacio de centralidad" < http://www.ciccp.es/biblio_digital/Urbanismo_I/congreso/pdf/050102.pdf $>$.

Mansilla, S. (2001), El desarrollo geohistórico de San Miguel de Tucumán. Una contribución a un modelo dinámico de la diferenciación funcional y socioespacial de las ciudades intermedias de América Latina, tesis de doctorado, Tucumán, Facultad de Filosofía y Letras, Universidad Nacional de Tucumán.

Mertins, G. (1995), "La diferenciación socioespacial y funcional de ciudades latinoamericanas: ejemplos del noroeste argentino", I Congreso de Investigación Social. Región y Sociedad en Latinoamérica. Su Problemática en el Noroeste Argentino, Tucumán, Universidad Nacional de Tucumán.

Mertins, G. (1998), "La suburbanización poblacional de Santa Fe de Bogotá, Colombia hacia la Sabana de Bogotá”, en G. Mertins y M. Czerny (coords.), Migraciones de la población latinoamericana y sus efectos socioeconómicos, Varsovia, Sociedad Polaca de Estudios Latinoamericanistas/Facultad de Geografía y Estudios Regionales, Universidad de Varsovia.

Mertins, G. (2003), “Transformaciones recientes en las metrópolis latinoamericanas y repercusiones espaciales”, en J.L. Luzón, C. Stardel y C. Borges (coords.), Transformaciones regionales y urbanas en Europa y América Latina, Barcelona, Universitat de Barcelona, pp. 191-207.

Müller, U. (2002), "El crecimiento urbano del Gran San Miguel de Tucumán entre 1965 y 1991”, Población y Sociedad, núm. 8 y 9, pp. 115-152.

Municipalidad de Yerba Buena (1994), Código de ordenamiento urbano, Tucumán. 
Paolasso, P. (2004a), Los cambios en la distribución espacial de la población en la provincia de Tucumán durante el siglo $\mathrm{XX}$, tesis de doctorado, Tucumán, Facultad de Filosofía y Letras. Universidad Nacional de Tucumán.

Paolasso, P. (2004b), Geografía de Tucumán, San Miguel de Tucumán, La Gaceta.

Prévôt Schapira, M. (2000), "Segregación, fragmentación, secesión. Hacia una nueva geografía social en la aglomeración de Buenos Aires", Economía, Sociedad y Territorio, núm. 7, pp. 405-431.

Roitman, S. (2003), "Barrios cerrados y segregación social urbana", Scripta Nova, vol. 7, núm. 146, p. 118.

Sassen, S. (2007), Una sociología de la globalización, Buenos Aires, Katz.

Svampa, M. (2003), Los que ganaron. La vida en los countries y barrios privados, Buenos Aires, Biblos.

Svampa, M. (2004), La brecha urbana. Countries y barrios privados, Buenos Aires, Capital Intelectual.

Taylor, S.J. y R. Bodgan (1990), Introducción a los métodos cualitativos de investigación. La búsqueda de significados, Buenos Aires, Paidós.

Tella, G. (2000), "La modernización de una metrópolis semiperiférica: el caso de Buenos Aires y sus transformaciones socio territoriales recientes", Scripta Nova, vol. 69, núm. 70.

Thuillier, G. (2005), "El impacto socioespacial de las urbanizaciones cerradas: el caso de la Región Metropolitana de Buenos Aires", Eure, vol. 31, núm. 93, pp. 5-20.

Vidal Koppmann, S. (2000), "Las urbanizaciones privadas: ¿una innovación para la transformación del territorio?”, Scripta Nova, núm. 69.

Vidal Koppmann, S. (2002), "Nuevas fronteras intraurbanas: de los barrios cerrados a los pueblos privados. Buenos Aires, Argentina", en L.P. Cabrales Barajas (coord.), Latinoamérica: países abiertos, ciudades cerradas, México, Universidad de Guadalajara, pp. 261-286.

Vidal Koppmann, S. (2006), "La articulación global-local o cuando los actores privados construyen una nueva ciudad”, Scripta Nova, núm. 10, p. 218. 